\title{
Trabajo social con grupos y sus dimensiones de intervención. Revisión documental en América Latina
}

\section{Diana Marcela Jiménez Martínez}

Aprobado:

30 de marzo de 2020

Recibido:

14 de junio de 2019

DOI:

http://dx.doi.org/10.18566/rfts.v34n34.a04
Trabajadora social de la Universidad Pontificia Bolivariana, especialista en Intervenciones Psicosociales de la Universidad Católica Luis Amigó, correo: marcelaupb@ gmail.com. Asesor Mg. Edison Francisco Viveros Chavarría,correo:edison.viverosch@amigo.edu.co 


\section{Resumen}

Este artículo de revisión tuvo como objetivo analizar la producción escrita sobre el método de trabajo social con grupos (TSG) en América Latina desde el año 2005 hasta el 2018. El enfoque de investigación fue cualitativo bajo una mirada histórico hermenéutica, apoyado de la estrategia documental y de técnicas e instrumentos basados en matrices, memos analíticos y análisis del discurso, revisando e interpretando una muestra total de 51 textos. Los resultados presentan y analizan las dimensiones de intervención teórica, metodológica y ético-política del TSG, que se constituyeron en las tres categorías de análisis de la investigación, concluyendo que las tres deben ser asumidas por las y los trabajadores sociales, en conjunto, para desarrollar acompañamientos grupales integrales.

Palabras clave

Trabajo social con grupos, Dimensiones de la intervención.

\section{Abstract}

This review article aimed to analyze written production on the method of Social Work with Groups (TSG) in Latin America from 2005 to 2018. The research approach was qualitative under a hermeneutical historical perspective, supported by the documentary strategy and of techniques and instruments based on matrices, analytical memos and discourse analysis, reviewing and interpreting a total sample of fifty-one (51) texts. The results present and analyze the dimensions of theoretical, methodological and ethical-political interventions of the TSG, which were constituted in the three categories of analysis of the research, concluding that the three should be assumed by the Social Workers as a whole to develop accompaniments integral groups.

Keywords

Social work with groups, Dimensions of the intervention 


\section{Introducción}

Desde la Federación Internacional de Trabajo Social (2014) se plantea una definición mundial frente al trabajo social, precisando que es una

profesión basada en la práctica y una disciplina académica que promueve el cambio y el desarrollo social, la cohesión social y el fortalecimiento y la liberación de las personas. Los principios de justicia social, derechos humanos, responsabilidad colectiva y respeto a la diversidad son fundamentales. Respaldado por las teorías del trabajo social, las ciencias sociales y las humanidades, el trabajo social involucra a las personas y las estructuras para hacer frente a desafíos de la vida y aumentar el bienestar (Consejo General del Trabajo Social, 2019, párr. 3).

Ampliando la idea de la Federación, el trabajo social, como disciplina, desea generar transformaciones sociales, potenciando las habilidades tanto de individuos y familias como de grupos y comunidades, fomentando e incrementado su bienestar social, identificando y movilizando sus recursos para hacer frente a su realidad, y motivando a su emancipación y conciencia crítica. Para lograrlo, uno de sus métodos de intervención es el trabajo social con grupos, el cual según López y Fernández (2006) "se orienta a recuperar y fortalecer, mediante la interacción grupal (...), las capacidades sociales de los ciudadanos, para aumentar su enriquecimiento personal y (...) social” (p. 48).

A partir de lo anterior, este artículo de revisión presenta los hallazgos de la investigación documental realizada en algunos países de América Latina acerca del trabajo social con grupos como método de intervención, identificando y destacando planteamientos académicos y prácticos desde las dimensiones teórica, metodológica y ético-política, las cuales trabajan en pro de apoyarlo, fortalecerlo y fomentarlo.

Ahora bien, es claro que existen fundamentos desde el trabajo social para realizar intervenciones con grupos humanos; sin embargo, pese a destacar su importancia, el interés por abordar esta temática se genera debido a que en los países latinoamericanos la producción científica, las investigaciones y las sistematizaciones de experiencias frente a este método han sido limitadas, en especial, en comparación con los otros métodos de la disciplina, por lo 
cual, aún algunas unidades académicas se basan en referencias exógenas, y también se realizan intervenciones desde teorías foráneas, muy diferentes al contexto propio, no permitiendo el cumplimiento de los objetivos propuestos. Lo planteado se convierte en una necesidad disciplinar frente a las revisiones del material existente y la creación de publicaciones constantes y actualizadas respecto al trabajo social y las intervenciones grupales de las y los profesionales.

Por ello, este artículo reúne elementos fundamentales para desarrollar y sustentar el trabajo social con grupos a partir de referencias latinoamericanas, al identificar y destacar la producción escrita frente al tema publicado de manera digital y física, contrastar textos de diferentes fuentes para conocer lo existente, evidenciar tendencias, actualizar la información y la producción de conocimiento, asimismo contribuir a la docencia universitaria para promover y fortalecer este método, y entregar elementos teórico-prácticos a las y los profesionales para realizar los acompañamientos e intervenciones desde el trabajo social grupal.

Si bien no ha sido un tema estudiado de forma constante como se mencionó anteriormente, en el ámbito nacional, la Universidad de La Salle y la Universidad Nacional con sedes en Bogotá, desde sus facultades de trabajo social han desarrollado investigaciones y libros en función del trabajo social con grupos, con autores como Bonilla, Curvelo, Jiménez, Torres y Umba (2005); López, Martínez y Peralta (2009); y Castellanos y Tijaro (2011). Y en el ámbito internacional con Dell'Anno y Teubal (2006); De Robertis y Pascal (2007); y Custo (2013). En los textos publicados por las autoras se destaca el método a partir de planteamientos teóricos, se recalca la importancia de los análisis de contexto y se presentan algunos elementos metodológicos y operativos para el abordaje grupal.

Esta investigación es un aporte más al método de trabajo social con grupos, reuniendo y permitiendo al lector una mirada general, considerando las dimensiones teóricas, metodológicas y ético-políticas, importantes para una intervención social integral a partir del trabajo social con grupos humanos.

Finalmente, el presente artículo se divide en cinco apartados. El primero presenta la metodología utilizada durante todo el proceso de la investigación; después se inicia la discusión y análisis de las categorías, destacando en el segundo apartado los referentes teóricos en los cuales se basa el trabajo 
social con grupos; en el tercero algunos aspectos metodológicos de la investigación; en el cuarto consideraciones ético-políticas; en el quinto diferentes experiencias de intervención grupal a partir del trabajo social; y, para terminar. se presentan las conclusiones de la investigación.

\section{Método}

El presente artículo se desarrolló a partir del enfoque investigativo cualitativo, el cual según Galeano (2004) "más que un conjunto de técnicas para recoger datos: es un modo de encarar el mundo de la interioridad de los sujetos sociales y de las relaciones que establecen con los contextos y con otros actores” (p. 16). Además, permite analizar la subjetividad de los procesos grupales y de los autores que desarrollan teorías e intervenciones con grupos, posibilitando el estudio de la literatura desde lo socio-histórico.

El enfoque metodológico elegido fue el histórico hermenéutico, definido por Cifuentes (2011) como un enfoque que busca "indagar situaciones, contextos, particularidades, simbologías, imaginarios, significaciones, percepciones, narrativas, (...) motivaciones, intenciones que se configuran en la vida cotidiana" (p. 30), propiciando la comprensión de los documentos revisados por medio de los análisis contextuales e históricos, y facilitando desde allí la interpretación de los mismos.

\section{Estrategia}

Respecto a la estrategia, se trabajó desde la investigación documental, la cual permite la revisión sistemática de documentos, con el fin de realizar un registro organizado y de actualizar la literatura que circula en el medio, relacionada con el tema de investigación específico (Vélez y Galeano, 2002), en esta oportunidad del TSG. 


\section{Muestra}

Según Hernández Sampieri et al. (2014) la muestra en las investigaciones cualitativas son un "grupo de personas, eventos, sucesos, comunidades, etc., sobre el cual se habrán de recolectar los datos, sin que necesariamente sea estadísticamente representativo del universo o población que se estudia" (p. 384). A partir de lo anterior, para la construcción de este artículo de revisión se investigó en las bases de datos Dialnet, Google Académico, Redalyc y Scielo respecto al TSG en Latinoamérica, localizando literatura en los países de Argentina, Colombia, Chile, Ecuador, Paraguay, Uruguay y Venezuela.

El periodo de tiempo revisado es el transcurrido entre los años 2005 al 2018, encontrando 35 documentos directamente relacionados con el TSG entre libros, artículos, ponencias, trabajos de grado y programas universitarios; los otros 16 textos son complementos que apoyaron la argumentación del proceso metodológico y la reflexión del objeto de investigación. En formato físico se revisaron los libros, y en formato digital los demás documentos.

\section{Instrumentos}

Para elegir los instrumentos que facilitaron el proceso de construcción y análisis del artículo, se tuvo en cuenta la matriz creada por Vélez y Galeano (2002) que explica el proceso metodológico de investigación. Conforme a ello, para registrar la información se crearon memos analíticos construyendo notas emergentes en los documentos revisados respecto a lo teórico, metodológico y ético-político como categorías de la investigación. Para generar información se realizó una lectura crítica de los textos, teniendo como base los procesos de sintaxis, semántica, semiótica y pragmática (Ricoeur, 2006, pp. 15-37).

Para organizar y sistematizar los hallazgos se crearon varias matrices: categorial, metodológica, de resultados y triangulación; esta última definida por Denzin (1970) como la combinación de varias teorías o datos para estudiar una situación particular; en este caso se agruparon los apartados más relevantes de los documentos que hacían alusión a las categorías mencionadas en función del TSG. Finalmente, el análisis crítico del discurso 
fue elegido para analizar e interpretar la información a partir de las lecturas intra, inter y extra textuales (Pérez, 1998, p. 239).

\section{Procedimiento}

Para la creación de este artículo, primero se identificó la temática a investigar y se revisaron las bases de datos mencionadas; después se organizó la información encontrada por medio de matrices que permitieron ordenar y agrupar lo hallado respecto al TSG; y, por último, se trianguló la información, analizando e interpretando lo recolectado desde diversos autores, a partir de las tres categorías centrales de la investigación.

\section{Resultados}

Este artículo se desarrolló a partir de la revisión de documentos referidos a la intervención del TSG en Latinoamérica, considerando tres categorías centrales como dimensiones fundamentales del trabajo social grupal, las cuales son: referentes teóricos, aspectos metodológicos y consideraciones ético-políticas. A continuación, se relaciona una tabla con las dimensiones de la intervención del TSG, los países latinoamericanos encontrados con producción respecto al tema, los documentos revisados con su respectivo número de textos y el total global. 
Tabla 11. Dimensiones de la intervención del TSG en Latinoamérica

\begin{tabular}{|c|c|c|}
\hline Categorías- dimensiones & País & Documentos \\
\hline \multirow{2}{*}{ Teórica } & Argentina & Libros: ocho \\
\cline { 2 - 3 } & Colombia & Ponencia: tres \\
\cline { 2 - 3 } & Chile & Artículos: trece \\
\hline \multirow{2}{*}{ Metodológica } & Ecuador & Trabajos de grado: Ocho \\
\cline { 2 - 3 } & Paraguay & Programas universitarios: tres \\
\hline \multirow{2}{*}{ Ético-política } & Uruguay & \\
\cline { 2 - 3 } & Venezuela & Treinta y cinco (35) \\
\hline
\end{tabular}

Fuente: Elaboración propia.

\section{Discusión}

En este capítulo se presentan los hallazgos de los documentos revisados acerca de las intervenciones grupales desde el trabajo social, y la interpretación y análisis de los mismos, exponiendo referentes teóricos del método, diversos aspectos metodológicos, consideraciones ético-políticas a tener presentes de las y los trabajadores sociales al realizar acompañamientos con grupos, y algunas experiencias de intervención a partir de este método.

\section{Acerca de las intervenciones desde el trabajo social con grupos}

La intervención profesional desde el TSG según Bonilla et al. (2005) "se sustenta en la construcción y desarrollo de la vida grupal; ha sido una fuente de enriquecimiento para promover el desarrollo personal y comunitario" (p. 202). De su parte, se encuentra la propuesta de López et al. (2009) quien hace referencia a que el modelo de intervención del TSG 
formaliza en procesos específicos, y bajo presunciones lógicas determinadas, el trayecto y la orientación particular de la acción profesional en un grupo, a través de objetivos y metas que delimitan los campos de experiencia que en la trama social del agrupamiento serán afectados (...). La transformación de las relaciones sociales particulares del grupo y el tratamiento del conflicto grupal, a través de las inercias y dinámicas de un grupo, constituyen el fin último del modelo de intervención (pp. 341-342).

Otra autora que destaca la estrategia de intervención profesional en el campo de lo grupal es Custo (2017), quien formula que esta

comprende una serie de componentes cuyo objetivo, por un lado, nos permite analizar las diferentes experiencias grupales y colectivas que se desarrollan en la realidad y, por el otro, la intervención en la que el "dispositivo grupal” se constituye en una forma de intervenir sobre las manifestaciones de la cuestión social, la cual se presenta a través de la compleja interrelación entre necesidades, relaciones sociales y representaciones sociales en el espacio de la vida cotidiana de los sujetos sociales (p. 7).

En estas propuestas que sustentan la intervención grupal desde el trabajo social, se logra extraer, de sus ideas centrales, la importancia de construir la vida grupal entre los participantes por medio de la interacción constante, teniendo claro que en ella se presentan conflictos que deben ser gestionados, pero que, a la vez, permiten consolidar al grupo; además, deja entredicho que estos acompañamientos se desarrollan, por lo general, a partir de realidades sociales complejas, por las cuales ellos atraviesan, lo cual le sugiere al profesional orientar al grupo y analizarlo a través de teorías y experiencias que conlleven al cumplimiento de objetivos específicos, y concluyan en las transformaciones individuales y sociales de los sujetos. 


\section{Referentes teóricos del trabajo social con grupos}

En este apartado teórico se expondrán varios elementos: de forma ágil el recorrido histórico mundial del TSG, la categoría grupo, algunos elementos contextuales acerca de la intervención grupal, definiciones y objetivos que persigue el método, modelos de acompañamiento con grupos, tipologías grupales y teorías de las ciencias sociales, de las cuales se apoya el TSG; todo lo anterior para sustentarse como un método de intervención del trabajo social.

Para hablar de la historia del TSG, su génesis y primeras manifestaciones se remontan a grupos durante la Revolución Industrial a partir de acciones familiares, vecinales y religiosas, cuyos antecesores son la Asociación Cristiana de Jóvenes, los Boy Scouts y los Settlement House -centros comunitarios- como procesos con experiencia en el trabajo con grupos, aunque con un enfoque recreativo y religioso (López et al., 2009, p. 32). Castellanos y Tijaro (2011), citando a Cifuentes et al. (2010), señalan como en 1946 en Buffalo, Nueva York, en la Conferencia Nacional de Trabajo Social se le reconoce como método de intervención, dándole fuerza al grupo como una alternativa de acción profesional con diversidad de propósitos, tanto preventivos y educativos como promocionales (p. 22).

En el contexto de América Latina, en 1945, en Santiago de Chile, se realizó el Primer congreso panamericano de servicio social, y allí se invitaron a todas las Escuelas del continente a incorporar este método en sus programas. De Robertis (1998), citada por Villa, Blanco y Navarro (2017), informa como en los años 70` con el proceso de reconceptualización y repensar del trabajo social a partir de las características y contextos propios latinoamericanos, operó la "integración de los métodos" o también llamado "enfoque genérico" proponiendo que los métodos clásicos (caso, grupo y comunidad) no eran incompatibles (p. 241). Con el pasar de los años, algunos países continuaron trabajando bajo este enfoque genérico mientras que otros retomaron los métodos por separado.

Actualmente, en los programas universitarios se proponen los tres métodos clásicos, cada uno con particularidades en su origen, consolidación, metodologías y lógicas de intervención, a partir de procedimientos 
investigativos, sistemáticos y organizados, que se consolidan y conjugan con intervenciones fundamentadas para acompañar las realidades sociales, ya sea de forma individual o colectiva, y generar transformaciones en estas.

De otro lado, para hacer referencia al TSG es necesario retomar el concepto de grupo como categoría fundamental, haciendo alusión a este como una organización o conjunto de dos o más personas que se relacionan e interactúan entre sí; además como agrega Pichon-Riviere (1988), citado en Alegre (2009), están "ligadas por una constante de tiempo y espacio, (...) y se proponen una tarea que constituye su finalidad, interactuando a través de complejos mecanismos de asunción y adjudicación de roles" (p. 5). Así mismo, el grupo cuenta con identidad, estructura, un tamaño determinado y los sujetos pertenecientes desarrollan una tarea específica, guiada por los objetivos establecidos (Maidana, s.f.), implicando constantes conflictos que permiten la construcción y el crecimiento grupal. Se destaca, finalmente, como los grupos se conforman a partir de las características propias de cada sujeto (Custo \& Bilavcik, 2016), uniéndose a otros por similitudes en su forma de ser o por situaciones semejantes (p. 2).

Ahora, lo que constituye lo grupal es el encuentro, la interacción y el intercambio con los otros y con lo otro, en palabras de Bilavcik y Custo (2017) es en el espacio de lo social donde se desarrollan múltiples experiencias grupales y colectivas (p. 1); o como lo complementan Bazán y Pérez (2013) "es el escenario donde se despliegan acciones para desarrollar habilidades, conductas y actitudes que favorezcan la trama vincular cooperativa" (p. 207). Oliva (2014), propone que, el trabajo social reconoce la fuerza del grupo e intenta canalizarla hacia una acción constructiva y transformadora que aporte al sujeto como ser individual y al grupo como realidad colectiva en el cumplimiento de sus objetivos (p. 276). Así, el TSG hace uso de esa fuerza del grupo para "fomentar la ayuda mutua y el desarrollo personal, y al grupo como micro- organización para promover la acción colectiva” (p. 279).

Para realizar intervenciones desde el TSG es indispensable hacer lectura del contexto (social, histórico, político, económico, cultural, institucional, familiar), pues como lo señala Bazán y Pérez (2013) "el contexto que contiene, es un texto que habla, que condiciona, que influye, que norma, que facilita u obstaculiza procesos, por lo que se debe observar en forma permanente en su interacción con el grupo" (p. 208). Así mismo, lo reafirma 
Maidana (s.f.) al mencionar que se deben tener en cuenta el tiempo, tamaño del grupo, localización, relaciones entre organizaciones e influencia sobre el entorno, para así comprender lo que sucede, explicar e intervenir sobre esa realidad particular. Además, Fernández (1985), citada en Simon, Colque, Rada, Carrizo, Cruz \& López (2018), afirma que "los grupos no son islas, sino que se inscriben en instituciones" (p. 184), por lo cual, el profesional requiere hacer lectura contextual desde todos los componentes al momento de iniciar un trabajo grupal, para conocer la realidad, y no interrumpir procesos adelantados por el colectivo y acompañarlos de forma asertiva.

\title{
Definiciones y objetivos del trabajo social con grupos
}

\begin{abstract}
Al TSG, a lo largo de su historia, lo han definido múltiples autores; en esta ocasión se retoman definiciones que lo sustentan y consolidan como método de intervención del trabajo social.
\end{abstract}

Gisela Konopka, una de las primeras profesionales que lucho porque la categoría "grupo" fuese incluida dentro del trabajo social, lo ubica como "un método del trabajo social que ayuda a los individuos a mejorar su funcionamiento social a través de experiencias de grupo planeadas y a hacer frente, de forma efectiva, a sus problemas personales, de grupos o comunidad" (Konopka, citada en Oliva, 2014, p. 278; García, Jaimes \& Melo, 2017, p. 145; Villa et al., 2017, p. 235).

De otro lado, Ander-Egg (2009) postula que es:

Uno de los tres métodos clásicos de la profesión a través del cual, utilizando la situación de grupos, se ayuda a que los individuos miembros de un grupo puedan satisfacer sus necesidades psicosociales y progresar desde el punto de vista emotivo e intelectual de modo que puedan alcanzar los objetivos del grupo y contribuir a un mejor funcionamiento de la sociedad (p. 258). 
Así mismo, Murphy (1959), citada en Villa et al. (2017), lo define como "un método de trabajo social que fomenta el desempeño social de las personas a través de experiencias grupales con objetivos específicos" (p. 235). Por su parte, Viscarret (2007), citado en Oliva (2014), sugiere como el TSG "proporciona un contexto en el cual los individuos se ayudan mutuamente; es un método para ayudar tanto a grupos como a individuos, para (...) que sean capaces de solucionar problemas personales, de grupos, de organización, y de la comunidad" (p. 278).

Finalmente, el Diccionario especializado de trabajo social (Montoya, Zapata y Cardona, 2002), citado por Villa et al. (2017), dice que es un

método del trabajo social que consiste en la organización y capacitación de grupos pequeños mediante procesos que impliquen una dinámica de grupo, orientados a enriquecer y mejorar el funcionamiento social tanto a niveles preventivos primarios como de tratamiento social. Gira siempre en torno a un grupo, pero sin desconocer las características de cada uno de sus miembros, contribuyendo al perfeccionamiento individual y a la consecución de objetivos sociales útiles (p. 236).

Estas definiciones, algunas con más antigüedad y otras son más recientes, tienen elementos en común que consolidan y le dan continuidad al método, al expresar, de distintas maneras, que la experiencia grupal es planeada e intencionada por parte del profesional, lo cual genera rigurosidad al proceso. De igual manera, se destaca que, si bien se trabaja de forma grupal con diversas personas, no se pierde de vista la identidad y las características de cada una de ellas, trabajando en pro del reconocimiento personal y del cumplimiento de los objetivos propios, paralelo al cumplimiento de los propósitos grupales, o como lo explicaran De Robertis y Pascal (2007), se realiza una intervención colectiva teniendo en cuenta la dimensión individual (p. 36). Además, se identifica que en la medida en que las personas reconocen sus habilidades y potencialidades, satisfacen sus objetivos y se relacionan con los demás, el contexto en el cual se encuentran también logra permearse por estos cambios, destacando que este método trabaja desde lo individual, lo grupal y lo colectivo, y resaltándolo como una forma de intervención integral. 
Ahora, el término "ayuda" tan nombrado en las definiciones presentadas, debe irse desplazando del discurso profesional y reemplazarse por palabras más propicias y técnicas, según el desempeño de las y los trabajadores sociales, como, por ejemplo, apoyo o acompañamiento, realizando una transición en el discurso y otorgándole al sujeto de intervención un lugar activo y de movilización en el proceso grupal. Así mismo, el "funcionamiento social", mencionado en varias oportunidades como una de las orientaciones del método de TSG, debe replantearse y pensarse como un proceso de intervención, como la manera de apoyar y reconocer la importancia del relacionamiento con los otros y con lo otro, y no como una forma de adaptación de las personas a la sociedad.

Continuando con las definiciones que sustenta el método de TSG y al indagar por la persona como ser individual que está inmersa dentro de un grupo, De Robertis (2003), citado en Oliva (2014), manifiesta que esta "no es ya una individualidad única y diferente a todas las demás, sino que, al mismo tiempo, es igual a todas las otras personas de su entorno social, tiene los mismos derechos, (...) en cierta medida, aspiraciones semejantes” (p. 286), destacando que al estar dentro del grupo, las personas continúan siendo ellas mismas con sus particularidades y singularidades, pero con elementos en común, que las unen con los demás, con lo cual se reconocen como un "nosotros" pertenecientes a un grupo.

Siguiendo en la línea de la fundamentación del TSG, este se propone diferentes objetivos como método de intervención con grupos humanos, presentando algunos de ellos.

Grace Coyle (1935), pionera del TSG, citada en Martínez \& Peralta (2006), expone que este tiende "al crecimiento del individuo y a su ajuste mediante la experiencia de grupo; al desarrollo del grupo hacia fines específicos; y a la acción social, cambio social o cambio de la sociedad por la experiencia de grupo” (p. 65). En la misma línea lo aborda la ONU (1962), citada por Oliva (2014), al destacar que el grupo se convierte en el instrumento gracias al cual, por un lado, los individuos hacen uso de él para satisfacer sus propias necesidades y, por el otro, apoyan al mismo grupo en la realización de acciones sociales que aportan a un colectivo de forma positiva (p. 276). 
En otra perspectiva, Teubal (2006) enuncia que desde el TSG se fortalece la autoestima, se reconocen los derechos ciudadanos, se promueven los lazos sociales, se sensibiliza frente a la aceptación de las diferencias, se aportan conocimientos específicos y se contribuye a la integración social (p. 59). De otro lado, Oliva (2014) sostiene que los objetivos del método se basan en "evitar el aislamiento, fomentar el aprendizaje y la madurez social, preparar a los miembros para las crisis o cambios vitales, resolver o aclarar problemas a nivel personal/familiar/del entorno del grupo, e influir a nivel social” (p. 279).

A partir de lo anterior, se concluye, en términos generales, que el TSG, desde sus intervenciones en diferentes contextos, desarrolla su accionar en pro del cumplimiento de objetivos en tres direcciones: individuales, grupales y sociales, haciendo énfasis en la experiencia intencionada del grupo y en las interacciones para el logro de las metas personales, la satisfacción de los propósitos grupales y las transformaciones colectivas, teniendo como foco el mejoramiento continuo de las personas en estos tres ámbitos.

\section{Modelos y tipologías desde el trabajo social con grupos}

Otro referente teórico que aporta al sustento y consolidación del método de TSG son los modelos de intervención, de los cuales se destacan las contribuciones de Yolanda López Martínez, Alejandra Roa, y Lady Peralta (2009), Cristina De Robertis y Henri Pascal (2007), María Teresa Gnecco (2005) y Jorge Torres (1988). Estos modelos serán descritos a continuación, sin embargo, no se profundizará en ellos.

Para López, Roa y Peralta (2009) según los objetivos del grupo, los modelos de intervención profesional se pueden orientar en tres sentidos: con "orientación funcional" al identificar procesos conflictivos dentro del grupo, relacionados con problemas personales, grupales e institucionalessociales, y promover el funcionamiento colectivo apropiado en estos ámbitos; "con orientación hacia colectivos y comunidades" enfocado en acciones educativas que propicien el pensamiento crítico, el reconocimiento de acciones colectivas asertivas, el empoderamiento y la defensa de los derechos 
humanos; y de "orientación terapéutica" al trabajar con personas que han pasado por momentos de sufrimiento, para lograr tramitar ese dolor a partir de la experiencia grupal (pp. 343-351).

Por otra parte, De Robertis (2003), citada en Oliva (2014), sugiere dos modelos de intervención grupal referidos al desarrollo personal y al desarrollo local; en el primero "la situación de grupo favorece el desarrollo personal de los miembros y la aparición de procesos de ayuda mutua" (p. 279), y el segundo se desarrolla cuando se debe hacer frente a los problemas colectivos. Asimismo, De Robertis y Pascal (2007) proponen un modelo de intervención social que se apoya en los conceptos de cambio, contradicción, interdependencia y equilibrio dinámico (pp. 39-52).

Gnecco (2005) presenta un modelo centrado en la tarea, el cual también es abordado por los otros métodos del trabajo social, enfatizando en la "realización de tareas que se asignan a una persona (...) dentro de un límite de tiempo, para alcanzar las metas de cambio establecidas. (...) La idea básica (...) es que las personas pueden, con su esfuerzo, solucionar sus problemas" (p. 191).

Finalmente, Torres (1988), citado en Castellanos y Tijaro (2011), expone tres modelos desde el TSG: el primero en función de las metas sociales, al mencionar que en un grupo las personas se reúnen con intereses similares y estos se satisfacen a partir de la identificación de diversas alternativas y de las aprobaciones de la institución en la cual se inscribe el grupo; el segundo es referido al modelo remedial, el cual "constituye una interacción con fines de tratamiento clínico, considerando el grupo como agente de cambio"; y el tercero el recíproco, entendiendo que la sociedad y el individuo se relacionan constantemente desde procesos de interdependencia, reconociendo que dentro del grupo "el individuo y el funcionamiento de la sociedad pueden nutrirse" (p. 23).

Así, los modelos de intervención grupal, desarrollados desde el trabajo social por diferentes autores, entregan a los profesionales "una representación o construcción intelectual simplificada y esquemática”, tal y como lo señala Ander-Egg (2009, p. 219), para posibilitar el abordaje de las situaciones grupales desde diferentes lentes, apoyando la interpretación a partir de diversas teorías. Ese conjunto ordenado de conceptos facilita 
a las y los trabajadores sociales, la identificación y el acompañamiento coherente del grupo según sus objetivos, sujetos, objetos de intervención y tiempos de encuentro.

Se destacan, de forma general, modelos referidos a propósitos sociales, terapéuticos-clínicos y reconocimiento personal, abriendo un abanico de posibilidades para que se retomen y sustenten los procesos grupales desde ellos, como una guía que orienta la intervención grupal a partir de las características propias del grupo.

Un referente teórico más que se retoma en las intervenciones desde el TSG son las tipologías grupales, las cuales permiten categorizar el grupo según sus características y naturaleza y, a partir de ello, desarrollar acompañamientos asertivos con conocimiento contextual del mismo. Algunos de estas se enuncian a continuación.

Kisnerman (1969), citado en Velásquez (2017), plantea las tipologías grupales según la edad o grupos etarios: escolar, adolescente, adultos y ancianos (p. 28). Desde otra perspectiva, Gnecco (2005) resalta los tipos de grupos primarios, secundarios, naturales y formados. Y en la misma línea, Torres (2002), citado en García et al. (2017), menciona los siguientes:

Describir si el grupo ha sido formado naturalmente o no; determinar la base de las relaciones grupales siendo formales o informales, como las condiciones específicas para el ingreso de los miembros conceptualizado desde un grupo cerrado o si no existen limitaciones denominado grupo abierto, también las características de los miembros evidenciará la homogeneidad o la heterogeneidad del grupo; de esta forma, el tamaño, la formalidad e informalidad, la naturaleza, tiempo de formación (...) y su grado de apertura indicarán si se trata de un grupo primario o secundario (p. 145).

Finalmente, desde la misma corriente que Gnecco y Torres, Contreras de Wilhelm (2003), citado en Velásquez (2017), clasifica las tipologías de los grupos en primarios y secundarios, naturales o espontáneos y obligatorios, motivados y reformados, formales e informales, organizados, abiertos y cerrados, y voluntarios (p. 24-25). 
Evidentemente, hay una vertiente teórica sobre los tipos de grupos que más se referencia por los autores revisados, abordada de forma dual y contradictora entre ellas. Identificar las tipologías le otorga al trabajador social conocimientos respecto a estas, para así lograr la interpretación de las características del grupo con el cual está trabajando y acercarse de manera acorde a su naturaleza.

\section{Aportes de las ciencias sociales al trabajo social con grupos}

El trabajo social no es el único que aborda a los grupos como objeto de intervención a partir de uno de sus métodos, de ahí que existan una diversidad de disciplinas junto con sus perspectivas desde las ciencias sociales que aportan teóricamente al análisis de la vida grupal. Al leer y examinar los documentos se identifica que el TSG se nutre de disciplinas como la antropología, la sociología, la psicología y la pedagogía para realizar análisis del espacio grupal, retomando de ellas teorías como: dinámica de grupos, sistémica, grupos operativos, de la comunicación, de conflictos, de la complejidad, el psicoanálisis, interaccionismo, funcionalismo, educación popular, pedagogía social y educación social. A continuación, se retoman elementos centrales de algunas, sin profundizar en ellas.

Una de las corrientes de las cuales hace uso el TSG es la teoría dinámica de grupos de Kurt Lewin (1951), citado en Simon et al. (2018), la cual se refiere al "juego de fuerzas y tensiones que regulan el campo psicológico del grupo y explican el comportamiento grupal" (p. 179); así mismo Cartwright (1983), citado en Alegre (2009), la plantea como las formas en que el grupo se va organizando (p. 4). Martínez y Peralta (2006) complementan que de esta teoría se utilizan los conceptos de liderazgo, clima grupal, estatus y comunicación, denominados elementos de la dinámica grupal, y algunas de sus técnicas como la sociometría y el psicodrama para analizar los fenómenos grupales (p. 67).

Lewin centró su atención en analizar las relaciones de interdependencia de los elementos, las cuales, finalmente, logran explicar el dinamismo del 
grupo (Villa et al., 2017, p. 237), contribuyendo así a los profesionales para "conocer, constatar, evaluar y sistematizar los fenómenos de relación que se despliegan tanto de manera intra como intergrupales" (Alegre, 2009, p. 7), teniendo como base las observaciones constantes en los procesos grupales.

La segunda teoría identificada y retomada es la sistémica de Bertalanffy, o la ecológica de Bronfenbrenner (Teubal, 2006; Asociación para el Avance del Trabajo Social con Grupo, citada en Oliva, 2014; Simon et al., 2018), la cual propone micro, exo y macro sistemas para analizar los grupos. Si bien esta teoría nació desde la biología, en las ciencias sociales y, en particular, en el TSG es de gran utilidad para analizar al grupo como un microsistema inmerso en un exosistema de instituciones y en un macro sistema más global que permite reconocer las ideologías y la cultura de las personas pertenecientes al grupo.

De otro lado, la tercera perspectiva es la teoría de grupos operativos de Enrique Pichon-Riviére (Simon et al., 2018, p. 179; Custo, 2017, p. 8; Méndez, 2017, p. 11) que "aborda al grupo a partir del desarrollo de un proceso de enseñanza-aprendizaje (...) donde el sujeto es el protagonista" (Alegre, 2009, p. 4), y la persona que acompaña al grupo es un facilitador. La noción de vínculo es importante para el autor, describiéndolo como una estructura que de forma paralela involucra a un sujeto y a un objeto, presentando mutuas interrelaciones a través de procesos comunicativos y de aprendizaje.

Otra de las teorías que aporta al TSG es la del conflicto, debido a que plantea que este siempre estará presente en los procesos grupales, y que como profesionales es fundamental entenderlo como un elemento característico de la vida de los grupos, pues es inherente a los seres humanos. Reconocerlo como "un elemento latente y un estado fundamental" como lo destaca Méndez (2017, p. 9) es importante, ya que genera movimientos y dinamización que aportan vida al grupo, ante lo cual no debe negarse o rechazarse cuando se manifieste, sino, por el contrario, abordarse.

Si bien el conflicto es reconocido como una oportunidad de crecimiento para el grupo, el mismo autor (Méndez, 2017) señala algunas estrategias de acción concretas para gestionarlo, como, por ejemplo, identificarlo, indagar por las causas, establecer conexiones con el contexto del grupo que compone lo 
conflictivo, promover el proceso grupal de resolución, y retomar el diálogo como principal herramienta de abordaje de los conflictos (pp. 14-15).

La educación popular de Paulo Freire es otra corriente teórica que ha aportado y nutrido con un tinte político latinoamericano al método (Villa et al., 2017, p. 237; Torcigliani \& Campana, 2009; Peralta, 2018, p. 124). Alfonso Torres (2007), citado en Peralta (2018), la describe a partir de cinco elementos centrales como:

Una lectura crítica del orden social vigente y cuestionamiento al papel integrador que ha jugado allí la Educación Formal; una intencionalidad política emancipadora frente al orden social imperante; un propósito de contribuir al fortalecimiento de los sectores dominados como sujeto histórico; una convicción que desde la Educación es posible contribuir al logro de esta intencionalidad; y un afán por emplear metodologías educativas dialógicas, participativas y activas (p. 125).

Peralta (2018), si bien está dirigiendo su discurso al trabajo social en general, el TSG, en particular, retoma estos cinco elementos de la educación popular para acompañar procesos grupales desde un rol activo en el empoderamiento de las personas dentro del grupo, con la intencionalidad de hacer uso consciente de técnicas participativas y constructivas, y con la idea de formar desde lo socio-pedagógico en aspectos puntuales necesarios del grupo; como lo menciona el mismo autor, el trabajo social y la educación popular se complementan: "ambas intervienen en la realidad social a partir de su comprensión crítica; ambas investigan y ambas educan” (p. 128).

Las teorías de las ciencias sociales mencionadas aportan constantemente al TSG conceptos y elementos para lograr analizar de forma más integral la vida grupal; cada profesional retoma las que considera más relevantes y que lo puedan apoyar en la explicación de los procesos grupales de la manera más amplia y posible.

Para concluir, la sustentación teórica es imprescindible por parte de las y los trabajadores sociales para dar fundamento a las intervenciones con y para los grupos humanos; esto permitirá el conocimiento y la apropiación de diversas teorías que apoyan los acompañamientos e interpretaciones 
grupales desde diferentes perspectivas, que a la vez se complementan y le dan un orden metódico y transdisciplinar al proceso grupal. Aquí es menester dejar claridad que todos los saberes de los sujetos participantes son valiosos y a partir de ellos también se construye con el grupo, respetando y valorando sus conocimientos y aportes a la vida grupal.

Finalmente, es importante resaltar que dependiendo de la temática o la realidad que se aborde en las sesiones grupales a partir de las necesidades materiales o simbólicas de los sujetos, estas serán investigadas por el o la trabajadora social para complementar su bagaje conceptual y teórico, ampliar su discurso frente a esa temática y aportar de forma clara en la construcción colectiva. Además, de manera simultánea el profesional debe trabajar en función del tema y, a la vez, en las relaciones e interacciones del grupo; o como lo ampliaría Custo (2013) "si la tarea explícita o temática es el aprendizaje de dichos temas, se tendrá en cuenta una tarea implícita para alcanzar una producción, recuperación de los saberes y construcciones de relaciones colectivas" (p. 6).

\section{Aspectos metodológicos del trabajo social con grupos}

En este apartado se abordarán aspectos de la dimensión metodológica para realizar acompañamientos grupales desde el trabajo social, según lo encontrado en el rastreo bibliográfico. Lo metodológico es entendido por Ander-Egg (2009) como la fundamentación de los métodos y como una estrategia de investigación, además el autor lo plantea en dos sentidos: desde la "metodología general (...) que se ocupa de estudiar los métodos generales empleados en las ciencias y la filosofía (...), y las metodologías especiales, ligadas a un cuerpo particular con que se alude a los procedimientos que utiliza una disciplina” (p. 216).

A partir de la segunda línea propuesta por Ander-Egg se presentarán los hallazgos e interpretaciones de esta revisión documental sobre la dimensión metodológica, teniendo claro que cada grupo es singular y estos no deben abordarse de la misma manera como fórmulas o recetas; sin 
embargo, es necesario conocer y desarrollar procesos de base metódicos para realizar intervenciones grupales de forma coherente y honesta, a partir de la identificación de los recursos y las fuerzas con las que cuentan las persona del grupo.

\section{Componentes de la intervención en trabajo social con grupos}

Se presentan a continuación tres propuestas identificadas en la literatura revisada acerca de los componentes de intervención del TSG, que profesionales sociales han desarrollado: de un lado Maidana (s.f.), de otro Custo (2009) y, finalmente, Castellanos y Tijano (2011), quienes retoman las ideas de Cifuentes, Pava, Rodríguez y Valenzuela (2001).

Maidana (s.f.) propone varios componentes a identificar y emplear en la intervención con grupos, los cuales permiten llevar a cabo un proceso claro y ordenado en los acompañamientos grupales. Estos mismos son retomados por Villa et al. (2017), quienes agregaron un componente más, denominado "resultados de la intervención", desarrollando un cuadro síntesis en el cual ubicaron experiencias concretas de intervención con grupos, realizando un análisis y sistematización de la información desde los componentes. Ellos son: situación grupal y problema particular; ideología, valores, conocimientos y experiencias previas del trabajador social; metodologías de intervención en los grupos; y conceptos, categorías, leyes y teorías explicativas de los grupos (Ver gráfico en Maidana, s.f., p. 7; y Cuadro sintético en Villa et al., 2017, p. 247).

Estos componentes permiten a las y los trabajadores sociales desarrollar intervenciones sistemáticas y claras, al identificar y plasmar la realidad social del grupo y el proceso implementado y construido con él. Se podría considerar agregar un componente más en función de las ideologías y valores de los sujetos con los cuales se trabaja, lo cual permitiría conocer más a fondo el contexto y los saberes previos de las personas. 
De otro lado, Custo y Tomasini (2009), citadas en Custo y Bilavcik (2016), enuncian unos componentes respecto a la estrategia profesional de intervención grupal, destacando los siguientes:

El "Contexto", categoría que intenta explicar el porqué de las condiciones sociales, económicas, políticas y culturales del espacio social donde se manifiestan las desigualdades; el "Problema Objeto de Intervención", sobre el cual se va a intervenir; los "Sujetos" con quienes se va a trabajar; y en "Donde" se desarrollan o promueven diferentes experiencias grupales para dar respuesta a las necesidades; el "Como" se va a intervenir (...); y, por último, cuáles son los "Objetivos del Trabajo Social” que se proponen con dicha intervención (p. 2).

Esta propuesta de componentes de intervención grupal tiene como elemento nuevo, la importancia de conocer el contexto de manera general y el lugar particular donde se trabajará con las personas, lo cual permite tener una referencia histórica-espacio-temporal al profesional. Así mismo, en ella se evidencia una influencia marxista en cuanto se busca analizar las diversas expresiones que tiene el capitalismo en la actualidad, más específicamente en América Latina, y evidenciar la tensión entre clases sociales que tanto enunciaron Marx y Engels (2011) en el Manifiesto comunista.

Para concluir, Castellanos y Tijaro (2011) exponen los componentes de intervención profesional que incorpora el TSG, retomando la propuesta de Cifuentes et al., (2001), pero ajustándolo en función del método. Los componentes a reconocer y llevar a cabo en los acompañamientos grupales son: los "sujetos" o participantes del proceso grupal; el "objeto" o situaciones, realidades y problemáticas sociales de la intervención; las "intencionalidades" o metas, objetivos y fines del trabajo con el grupo; y el "método de trabajo social con grupos", el cual abarca el origen, definición, autores, fines del método, propósitos (sociales, grupales y personales), momentos, técnicas y enfoques, considerando los últimos, según las autoras, como la dimensión operativa del método (p. 13).

Se resalta de esta propuesta que expone un abordaje y una descripción más amplia y específica respecto al componente del método de TSG, dejando 
claridades sobre lo que se debe identificar y plasmar en este ítem, al momento de hacer intervenciones y análisis grupales.

Al revisar las tres propuestas, que presentan algunos componentes similares y otros diferentes para tener en cuenta en los procesos de intervención grupal desde el trabajo social, se propone que ellas pueden complementarse y aportar a la construcción de una propuesta general que unifique y agrupe todos los elementos desarrollados por las autoras, para así crear una sola que permita análisis integrales y completos respecto al TSG. La propuesta sería la siguiente:

Figura 1. Componentes de la intervención en trabajo social con grupos

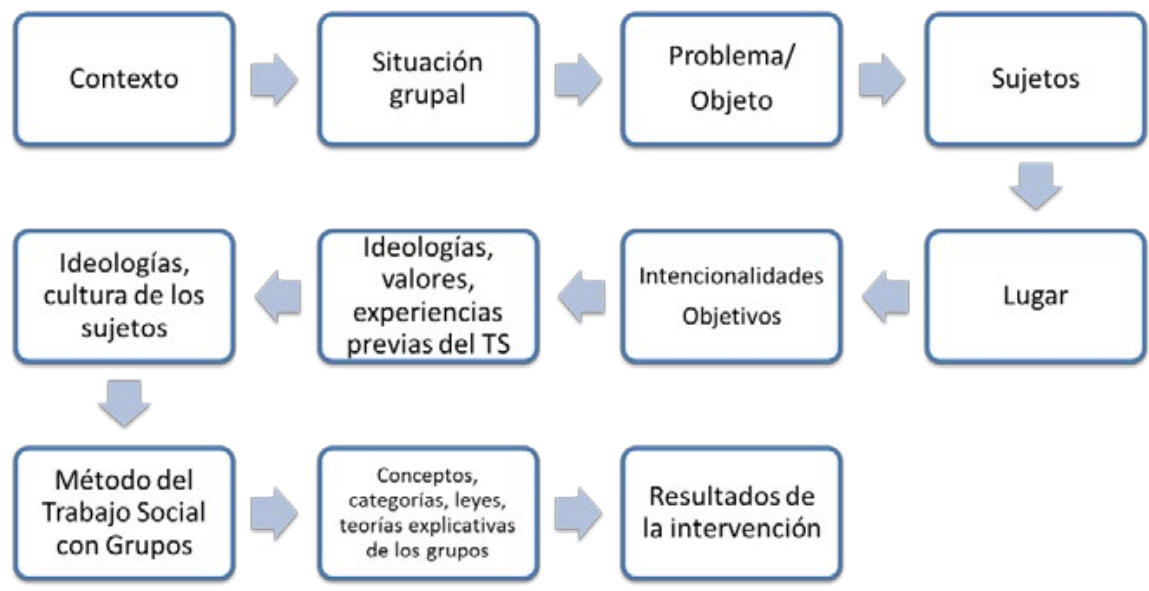

Fuente: elaboración propia.

\section{Fases o etapas y momentos del trabajo social con grupos}

Otro de los elementos que componen los aspectos metodológicos del TSG son las fases o etapas por las cuales atraviesa el proceso grupal en 
su trayectoria en el tiempo. La siguiente tabla presenta algunos autores encontrados en la revisión documental y las fases y etapas que formulan para realizar inversiones grupales desde el trabajo social.

Tabla 2. Fases o etapas grupales

\begin{tabular}{|c|ll|}
\hline Autor (a) & \multicolumn{1}{|c|}{ Fases-Etapas } \\
\hline (como se citó en Gnecco, 2005) & 1. & Inicial \\
& 2. & Formativa \\
& 3. & Intermedia I \\
& 4. & Revisoría \\
& 5. & Intermedia II \\
& 6. & Madurez \\
& 7. & Terminal (p. 71) \\
\hline Tschorne (como se citó & 1. & Inclusión y seguridad en situación o formación \\
en Sepúlveda \& Vásquez, 2015) & 2. & Estructuración \\
& 3. & Desarrollo de la participación y afecto \\
& 4. & Autorregulación del funcionamiento del grupo \\
& 5. & Disolución del grupo (p. 47-48) \\
\hline Rozas Pagaza (como se citó & 1. & Inserción \\
en Peccacq et al., 2018) & 2. & Diagnóstico \\
& 3. & Planificación y Ejecución (p. 5) \\
\hline Veléz (como se citó & 1. & Diagnóstico \\
en Castellanos \& Tijaro, 2011) & 2. & Planificación \\
& 3. & Sistematización \\
& 4. & Ejecución \\
& 5. & Evaluación (p. 44) \\
\hline Bonilla et al. (2005) & 1. & Idenficar la problemática \\
& 2. & Diseñar la solución \\
& 3. & Evaluar el proceso \\
& 4. & Sistematizar la experiencia (p. 202) \\
\hline Maidana (2005) & 1. & Encuadre y recorte del problema \\
& 2. & Estrategias de intervención \\
& 3. & Comprensión y explicación \\
& 4. & Estrategias de intervención (p. 7) \\
\hline & & \\
\hline
\end{tabular}




\begin{tabular}{|c|ll|}
\hline Autor (a) & \multicolumn{2}{|c|}{ Fases-Etapas } \\
\hline De Robertis y Pascal (2007) & 1. & Problema social colecctivo \\
& 2. & Análisis de la situación \\
& 3. & Reconocimiento de los grupos \\
& 4. & Reconocimiento de los participantes \\
& 5. & Evaluación diagnóstica \\
& 6. & Proyectos de intervención \\
& 7. & Ejecución del proyecto \\
& 8. & Evaluación de los resultados \\
& 9. & Clausura-fin de la intervención (p. 68-78) \\
\hline Villa et al. (2017) & 1. & Estudio preliminar \\
& 2. & Diagnóstico \\
& 3. & Planificación \\
& 4. & Sistematización (p. 240) \\
\hline Ruiz, Zelayarán y Jurado (2017) & 1. & Observación y descripción \\
& 2. & Análisis y reflexión \\
& 3. & Comprensión y aplicación de la intervención (p. 7) \\
\hline Contreras (como se citó & 1. & Formación \\
en Velásquez, 2017) & 2. & Integración grupal \\
& 3. & Organización \\
& 4. & Muerte del grupo (p. 66) \\
\hline
\end{tabular}

Fuente: elaboración propia.

Se evidenció a partir del rastreo bibliográfico que, si bien la mayoría de las etapas o fases grupales son enunciadas de forma diferente, en general se pueden agrupar y presentar de la siguiente manera: estudio preliminar del contexto y del grupo o diagnóstico; diseño o planificación de la propuesta o programa grupal; ejecución o intervención con el grupo, donde se identifican fases intermedias en el desarrollo de la intervención como el inicio o conocimiento entre las personas del grupo y el profesional, cuya interacción entre los sujetos puede conllevar conflictos, la consolidación del grupo, y la finalización de los encuentros grupales; evaluación del proceso, invitando a las y los profesionales a desarrollar constantemente seguimientos durante todas las fases; y sistematización e informes del acompañamiento grupal.

Estas etapas de la vida grupal permiten a las y los trabajadores sociales llevar a cabo acompañamientos procesuales que es ideal atravesarlas todas, para 
desarrollar intervenciones completas; cabe mencionar que en cada una de estas etapas se presentan roles profesionales diferentes según va avanzando el proceso del grupo, pero que no serán abordados en este artículo.

Ahora bien, las intervenciones grupales llevadas a cabo por parte de las y los profesionales varían en el número de sesiones de acuerdo con el objetivo, motivaciones, intenciones y temática o realidad que se afronte, entre otros elementos; no obstante, sin importar la cantidad de sesiones, por lo general, siempre se desarrolla el encuentro grupal a partir de tres momentos básicos: apertura, desarrollo y cierre. Hay otros autores que haciendo uso del taller reflexivo introducen más momentos como el encuadre, técnica inicial, desarrollo del encuentro, plenaria, retroalimentación y cierre. En esta oportunidad se hará referencia a los momentos básicos, que son sustentados por Bazán y Pérez (2013).

El primer momento es la apertura, que (...) es el comienzo, donde se instalan las bases para el devenir del encuentro. Por lo que en este momento se deben tener en cuenta aspectos de incorporación, disposición, ritmos, tiempos etc. En un segundo momento se despliegan las acciones que se pretenden generar en el encuentro y es lo que se puede denominar nudo central. Aquí se discuten ideas, se seleccionan alternativas y se construyen consensos, acordando acciones tendientes al logro del propósito del encuentro. Se diferencia un tercer momento, el cierre donde el coordinador a partir de lo observado hace la devolución y los miembros efectúan la evaluación del encuentro (p. 208).

Los momentos del encuentro grupal brindan orden al proceso y proporcionan tiempos para el desarrollo coherente y estructurado del mismo; allí es importante que el profesional aprenda a manejar los tiempos con los cuales cuenta y a ser consciente de que el paso de uno a otro es manejado por el mismo, a partir de las contribuciones de los participantes. 


\section{Técnicas e instrumentos de registro grupales}

De otro lado, aportando a los aspectos metodológicos del TSG se destacan las técnicas grupales, las cuales según Ander-Egg (2009) son un "conjunto de medios y procedimientos que, utilizados en situación de grupo, sirven para desarrollar y potenciar el trabajo (...), y (...) facilitar la participación de los miembros del grupo" (p. 334). Así mismo, Bazán y Pérez (2013) manifiestan que "metafóricamente podemos designar a estos elementos como las diferentes llaves que están contenidas en la caja de herramientas del Trabajador Social” (p. 204). Las técnicas grupales permiten realizar trabajos intencionados, con objetivos claros, convirtiéndose, por momentos, en reflejos de la realidad para posibilitar la reflexión constante de los participantes del encuentro grupal.

Estas han sido descritas y categorizadas por varios autores según las fases grupales, los momentos del encuentro o la población sujeto de intervención. Bonilla et al. (2005) proponen técnicas grupales de procedimiento, interacción, conducción directiva y no directiva, de participación y evaluación (pp. 193203); por otra parte, Bazán y Pérez (2013) enuncian técnicas de dinámica grupal, observación, dialógicas y de registro (p. 204); Ander-Egg (2009) expone técnicas de iniciación, producción, medición y evaluación (p. 334335); igualmente De Robertis y Pascal (2007) sugieren técnicas de animación (p. 303), transmisión de información e investigación; y Gnecco (2005) recomienda técnicas por medio de juegos, dramatizaciones, manualidades, música y salidas de campo. Cada una de estas técnicas generales contiene diversas sub-técnicas que aportan a la construcción e interacción entre los participantes para el desarrollo de los encuentros grupales y la consecución paralela de los objetivos.

De forma más general se plantean técnicas como la observación y la comunicación, las cuales apoyan al profesional, a partir del uso de los sentidos, en la identificación de las relaciones y las dinámicas grupales, al reconocer los gestos, el tono de voz, las posiciones corporales y la disposición espacial entre los miembros del grupo; además esta "debe ser una acción planificada, que responda a un objetivo y esté basada en un marco teórico determinado" (Bazán \& Pérez, 2013, p. 206). 
Cabe mencionar, que las técnicas elegidas por las y los profesionales para la operativización del trabajo grupal dependen de la población, el espacio, los recursos y la temática o realidad a trabajar; hay libros que proponen gran cantidad de técnicas grupales como, por ejemplo, el elaborado por García, González, Quiroz y Velázquez (2002); sin embargo, es fundamental adaptarlas al grupo y al contexto de una manera adecuada para lograr los objetivos propuestos y generar reales influencias y aprendizajes en los sujetos. Las técnicas son solamente herramientas o medios para el acercamiento y la dinamización del grupo, el objetivo está en desarrollarlas y socializar, interactuar, reflexionar, construir y transformar a partir del uso de ellas.

Finalmente, están los instrumentos que facilitan la recolección de la información que se construye en el encuentro grupal y el análisis. Maidana (s.f.) menciona los cuadernos de campo, las crónicas y los informes; Pessacq, Castro, Contreras y Triguero (2018) destacan las guías de entrevistas, de observación y diarios de campo (p. 7); Gnecco (2005) presenta una matriz para analizar el "Perfil de comportamiento de los miembros de un grupos" dividiéndola en cuatro partes: nombre de la persona, rasgos principales, fortalezas y debilidades en el comportamiento (Ver Matriz, p. 118); y García et al. (2017) comparten un "Protocolo metodológico" el cual está separado en las dimensiones metodológica, epistémica y práctica (Ver Protocolo, p. 169).

Respecto a la observación como técnica facilitadora de la identificación de los elementos grupales, se presentan dos instrumentos referidos a ella. Por un lado, Bazán y Pérez (2013) proponen un "protocolo para la observación” (Ver Protocolo, p. 201-217), el cual tiene como objetivo "orientar al observador sobre aspectos a tener en cuenta al emprender su tarea. Tiene como base los sucesos de la realidad grupal que se van develando en cada encuentro" (p. 208).

De otro lado, Lockett (2006) propone una “Guía de observación grupal” (Ver Guía en Dell'Anno y Teubal, pp. 146-147) en la cual se describen encuentros, fecha, asistentes, tema, evaluación, cumplimiento de lo planificado, aporte de las técnicas al cumplimiento de los objetivos, desarrollo teórico, dinámica grupal, elementos significativos mencionados por los participantes y cambio en el punto de vista.

Para concluir, De Robertis y Pascal (2007) presentan una guía denominada "Pautas de análisis de un grupo", la cual agrupan en tres segmentos. El 
primero es la descripción del grupo, el segundo se refiere al funcionamiento externo del grupo presentando la pertenencia de cada miembro a otros grupos y las relaciones con organismos e instituciones, y en el tercero se desarrolla un análisis de los procesos de comunicación, interacción, influencia, toma de decisiones y resolución de conflictos (Ver Guía, pp. 217-219).

Los instrumentos proporcionan al trabajador social elementos puntuales para recoger la información e identificar, interpretar y plasmar lo construido en el encuentro grupal, teniendo claro que estos son guías o esquemas que pueden ser ajustados en función de lo que requiera analizar y obtener el profesional para su trabajo. Estos instrumentos, finalmente, aportan en la consolidación y construcción de los informes sociales.

\section{Consideraciones ético-políticas del trabajo social con grupos}

Al momento de acompañar sujetos y grupos humanos, por lo general, en condiciones desfavorables, las posturas éticas deben estar presentes y ser asumidas por los profesionales en todo momento, en los que los modos de ser y el carácter de cada uno debe estar dirigido hacia la humanización, el reconocimiento y el respeto hacia los otros y lo otro. Se destacan a continuación algunas consideraciones ético-políticas para los trabajadores sociales que desarrollan procesos grupales, halladas en la revisión documental.

El método de TSG, al ser parte del trabajo social, comparte los mismos principios éticos de este, los que hace un tiempo Biestek (1966), citado en Surianu (2010), precisó en la individuación y los cuales son: expresión intencionada de sentimientos, participación emocional controlada, aceptación, actitud exenta de juicios, autodeterminación y reserva. Estos son los más reconocidos por las y los profesionales y estudiados de forma general en las unidades académicas.

Desde una perspectiva más amplia, el Consejo Nacional de Trabajo Social de Colombia (2015) en el Código de Ética señala que los principios sobre los que se fundamenta el accionar profesional, van en la misma dirección de la 


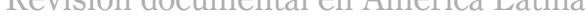

Constitución Política (1991) y de la Declaración Universal de los Derechos Humanos (1948), enunciando la justicia, dignidad, libertad, igualdad, respeto, solidaridad y confidencialidad (pp. 22-24). Y en la misma línea, la Federación Internacional de Trabajadores Sociales, citada en Gnecco (2005), y Oliva (2014), reconoce la dignidad humana, los derechos humanos, la justicia social y la solidaridad como valores fundamentales en las intervenciones sociales (p. 285).

Por otra parte, Oliva (2014) reclama que "los sujetos sociales han de ser vistos por él y la trabajadora social como ciudadanos capaces de cambio y de apoyar a los demás, haciendo énfasis en el empoderamiento" (p. 286). Lo cual se complementa con los aportes de García, citado en Bazán \& Pérez (2013), al plantear que el profesional "trabaja "junto" al grupo y no "para" ni "por" el grupo (...). Sitúa a este rol en un contexto de asimetría respecto de los integrantes" (p. 204). Y se refuerza con lo descrito por Custo (2013) al enunciar que se debe "pensar al sujeto como constructor de su propia historia, de sus hechos y derechos" (p. 2).

A los elementos anteriores es fundamental considerarlos desde el acompañamiento profesional grupal, para situar a las personas como sujetos activos y conscientes del proceso, y no como objetos, lo que cambia la perspectiva de intervención, y, realmente, generar empoderamiento y transformaciones en ellos.

Otras consideraciones ético-políticas relevantes desde las intervenciones del TSG son promover en los encuentros grupales el pensamiento reflexivo y crítico de los sujetos hacia su propia condición individual y social (Bilavcik y Custo, 2017, p. 549), proponiendo espacios de debate que generen análisis contextuales y posibles alternativas frente a las situaciones actuales de injusticia y desigualdad social. Además, fomentar en las personas "un pensamiento crítico, flexible, creador, dándose a la identificación, reconocimiento y conciencia de sus necesidades y a la organización para satisfacerlas, a través de la participación, el diálogo, la cooperación y la solidaridad" (Ruiz et al., 2017, p. 5). Y así mismo, concientizarlos respecto a la importancia de la transformación (Peralta, 2018) en función de los cambios personales y colectivos (p. 131).

De otro lado, Custo y Bilavcik (2016) proponen a los profesionales "construir un pensamiento creativo, ya que el mismo está ligado a la construcción y 
producción de subjetividades que desarrollen la autonomía (...), fortaleciendo además un compromiso intelectual, social y profesional” (p. 4); e, igualmente, invitan a "reflexionar conjuntamente con el grupo, trabajar sobre los obstáculos presentes en las relaciones (...) y favorecer un pensamiento crítico, autónomo y creativo que posibilite la resolución de los problemas” (p. 8).

Ahora, varios autores han propuesto, de forma particular, un listado de principios éticos que deben tener presentes los profesionales al momento de realizar intervenciones desde el TSG. Vinter (1969), citado en López et al. (2009), enuncia la individualización y socialización (p. 35); López et al. (2009) resaltan la autodeterminación y, de nuevo, la individualización (p. 50); de igual manera, Contreras de Wilhelm (2003), citada por Velásquez (2017), sugiere los siguientes principios: la democracia, individualización, no juzgamiento, establecimiento de una relación cordial, respeto de los intereses individuales, generación de bienestar social, mantenimiento de la fe en los miembros del grupo, no hacer proselitismo, mostrar madurez emocional y guardar el secreto profesional (pp. 47-48).

Gisela Konopka, citada en Velásquez (2017), presenta como principios básicos la individualización en el grupo, individualización de los grupos, aceptación de cada individuo, establecimiento de una relación de ayuda, cooperación entre los miembros del grupo, modificación apropiada del proceso grupal, estímulo a cada miembro para participar, capacitación en la solución de problemas, ofrecimiento de experiencias nuevas, evaluación del progreso individual y grupal, y cordialidad (p. 46).

Por otra parte, la Asociación para el Fomento del Trabajo Social con Grupos (2006), que es una entidad internacional, reconoce como consideraciones éticas la comprensión y uso de las mejores prácticas para reflejar la situación actual y la realización de investigaciones sobre el TSG, consentimiento informado, autodeterminación y poder del grupo, confidencialidad, apoyo al grupo a mantener los objetivos por los que se formó, apoyo a cada miembro, aclaración en procesos de toma de decisiones y selección o exclusión de miembros, y registro del grupo (pp. 26-27).

Para concluir, hay que expresar cómo las anteriores propuestas, acerca de las consideraciones ético-políticas al intervenir con grupos desde el trabajo social, son importantes para el profesional, ya que lo ubican en un lugar de 
apoyo, sensibilización y empoderamiento de los sujetos con los cuales trabaja, a partir de procesos socioeducativos, socio-terapéuticos y de encuentro grupal en los cuales realiza reflexiones contantes de las situaciones actuales y de sus derechos individuales y sociales, desde una postura democrática y emancipadora. También, es relevante mencionar que estas consideraciones deben ser discutidas desde la academia con los estudiantes universitarios y no solamente al momento de realizar trabajos de campo, además reconocer el contexto en el cual se está interviniendo, permitiendo un acercamiento ético-contextualizado con el grupo.

Finalmente, en función de esta dimensión se deja una invitación a los profesionales por parte de Paulo Freire (1976), citado en Peralta (2018):

Es necesario, todavía, que el trabajador social tome en cuenta que la estructura social es obra de los hombres. Esto significa que la tarea fundamental de ellos es la de ser sujeto y no objetos de la transformación. Tarea que le exige, durante su acción y sobre la realidad, la profundización de su toma de conciencia de la realidad, objeto de acciones contradictorias de quienes pretenden mantenerla como está y de quienes pretenden transformarla (p. 131).

\section{Experiencias de intervención a partir del trabajo social con grupos}

Para finalizar, se enunciarán algunas experiencias concretas que han sido desarrolladas desde el método de TSG encontradas en la revisión documental, invitando a conocerlas de manera más detallada a partir de su lectura desde la fuente.

- La práctica educativa del trabajo social en un contexto de encierro (Oliva, 2014).

- Trabajo social y construcción de paz: un abordaje a las representaciones sociales del grupo de jóvenes escolares del Proyecto Rumbo de Paz (García et al., 2017). 
- Trabajo social con grupos en las experiencias formativas. Periodos académicos 2015-2016 (Villa et al., 2017).

- El método de trabajo social en grupo en los proyectos de intervención de práctica de entrenamiento profesional (PEP) Universidad de La Salle 2000-2004 (Bonilla et al., 2005).

- Educación popular y justicia comunitaria. Reflexiones desde el trabajo social (Peralta, 2018).

- La práctica de trabajo social con Grupos en el proceso de implementación de la Licenciatura en Trabajo Social en la FHYCS de la UNJU: Una experiencia de intervención (Simon et al., 2018).

- Caracterización de los componentes de intervención profesional en los proyectos de práctica de entrenamiento profesional que incorporan el método de trabajo social de grupo. Programa de Trabajo Social, Universidad de la Salle, 2005-2010 (Castellanos \& Tijaro, 2011).

- Educación ambiental basada en el uso eficiente y seguro de la energía en diez instituciones educativas de Cartagena de Indias (Marrugo, 2012).

- Trabajo social con grupos: un análisis descriptivo del quehacer profesional en el área de salud mental (Sepúlveda \& Vásquez, 2015).

- Sistematización de experiencias de la práctica de trabajo social con grupos perteneciente a la Asociación Amigos con Calor Humano, Medellín 2015 (Valencia, 2015).

- Fortaleciendo la participación ciudadana, promoción de los derechos humanos. Informe final de la práctica profesional Corporación Conciudadanía (Zapata, 2016).

- La intervención de trabajo social en el proyecto Fortalecimiento de la educación sexual en adolescente. Institución Educativa Soledad Acosta de Samper, de Cartagena (Blanco, 2016).

- Informe final práctica académica de Trabajo Social III, centro gerontológico Dejando huellas, Santa Fe de Antioquia (Varela, 2016).

- La experiencia de un grupo de mujeres en una casa de acogida: en busca de un punto de encuentro (Lockett, 2006).

\section{Conclusiones}

A partir del análisis de la revisión documental, la experiencia y el aporte de Ruiz et al., (2017) quienes reconocen que "el ser humano solo se construye 
como tal a través del otro o sea a través de lo grupal” (p.3), se concluye que las intervenciones desde el TSG son pertinentes, acordes y actualizadas, permitiendo con ellas crear relaciones sociales solidarias y cooperativas, confrontar y gestionar conflictos, organizar las ideas colectivas, trabajar unidos por los objetivos comunes y socializar, este último como elemento necesario y fundamental de toda persona para convivir en sociedad.

Se reconoce al TSG como un método que integra y conecta los demás métodos del trabajo social, pues si bien posibilita la construcción y el desarrollo de la vida grupal, de forma paralela involucra al sujeto inmerso en el grupo, sus necesidades y potencialidades desde el trabajo social con individuos; reconoce además las estructuras y dinámica familiar de este a partir del trabajo social con familias, e identifica sus redes de apoyo y acciones colectivas desde el trabajo social con comunidad. Lo anterior permite acompañar, de manera integral, el proceso de transformación, destacando lo grupal como un espacio multidimensional.

En la época actual, enmarcada en el modelo capitalista, individualista, egoísta y consumista, el trabajo en y con grupos humanos, especialmente en Latinoamérica, proporciona espacios para el encuentro con el otro, el intercambio de saberes y experiencias, la creación conjunta de alternativas frente a problemas sociales, la confrontación y reflexión sobre la realidad actual injusta e inequitativa, y el apoyo mutuo, que en las instancias actuales y, en gran medida, se han perdido. Igualmente, este permite el reconocimiento de las subjetividades, dando un posicionamiento político al TSG, apoyando las resistencias sociales y rescatando la esperanza como elemento clave para el cambio social, tal y como lo manifiesta Custo (2017), citando a Eagleton (2016), al expresar que esta "requiere reflexión y compromiso que surge de la racionalidad y que reconoce el fracaso y la derrota, pero se niega capitular ante ellos” (p. 8).

Frente a las dimensiones de intervención del TSG se concluye que desde lo teórico el método cuenta con sustentos que le permiten intervenir y analizar la vida grupal, apoyado, así mismo, de disciplinas y conceptos de las ciencias sociales; no obstante, las teorías propias son limitadas y algunas de ellas formuladas con cierta antigüedad, por lo cual se invita a las y los trabajadores sociales, que en la academia y la práctica hacen 
uso y se apropian del TSG, a construir nuevas teorías que aporten a las intervenciones e interpretaciones desde este método.

A partir de la dimensión metodológica -u operativa, como algunas autoras la nombran-, esta cuenta con aportes claros y metódicos para el desarrollo del proceso grupal, presentando a las y los profesionales tanto componentes, fases y momentos de la intervención como técnicas e instrumentos que apoyan los programas grupales para ser llevados a cabo, y aportan, además, elementos para el análisis de las relaciones y el espacio grupal.

Desde la dimensión ético-política se identificaron aspectos fundamentales para desarrollar intervenciones honestas y empoderadoras con y en los grupos humanos, destacando como relevante el papel del profesional al reconocer a los participantes como sujetos activos del proceso grupal y no como seres pasivos que esperan recibir todo. Lo importante en esta dimensión es que las y los trabajadores sociales reconozcan y se apropien de los aspectos planteados para implementar intervenciones reflexivas, contextualizadas y socio-políticas, en el que este crea en el poder de transformación del grupo y se implique con él.

Las y los profesionales que desarrollan sus intervenciones desde el método de TSG pueden plantear acompañamientos grupales desde un enfoque psicosocial (Ander Egg, 2009; Villa et al., 2017; y Teubal, 2006), teniendo en cuenta el contexto y los sujetos, además de las relaciones horizontales entre ellos; depende del profesional retomar los aportes de este enfoque.

Respecto a lo académico, en función de la producción del TSG, es importante resaltar el trabajo desarrollado por la Universidad de la Salle con sus investigaciones sobre los proyectos de práctica de las y los estudiantes desde el método. Esta es una invitación a que las demás unidades académicas del país se vinculen y desarrollen este tipo de proyectos, ya sea desde la asignatura, las prácticas profesionales, las pasantías, y los grupos o semilleros de investigación, lo cual consolidará con más fuerza y sustento el TSG. 


\section{Referencias}

Alegre, S. (2009). El trabajo social en el campo de lo grupal. KAIROS Revista de Temas Sociales, (24), 1-8.

Ander-Egg, E. (2009). Diccionario del trabajo social. Córdoba, Argentina: Editorial Brujas.

Asamblea Nacional Constituyente. (1991). Constitución Política de Colombia. Gaceta Constitucional.

Asociación para el Fomento del Trabajo Social con Grupos, S.A. (2006). Estándares para la práctica del trabajo social con grupos. http://www.aaswg.org/files/Standards-Spanish.pdf

Bazán, L.C., y Pérez, C.B (2013). Re-creando la intervención con grupos a partir de la observación. Revista Dos Puntas, (8), 201-217.

Biestek, F. (1966) Las relaciones del Casework. Editorial Aguilar.

Bilavcik, C., y Custo, E. (2017). Lo grupal y lo colectivo como estrategia de resistencia para el fortalecimiento de los derechos en la contemporaneidad. En Universidad Nacional de Córdoba, Quinto encuentro argentino y Latinoamericano de Trabajo Social. Latinoamérica hoy: democracias, derechos y trabajo social (pp.546-552). Universidad Nacional de Córdoba. https://sociales.unc.edu.ar/sites/default/files/E\%20Book\%205to\%20Encuentro_0.pdf

Blanco Rivera, J.S. (2016). La intervención de trabajo social en el proyecto "Fortalecimiento de la educación sexual en adolescente. Institución Educativa Soledad Acosta de Samper de Cartagena. [Trabajo de pregrado, Universidad de Cartagena, Colombia]. https://repositorio.unicartagena.edu.co/bitstream/handle/11227/3885/FORTALECIMIENTO\%20 DE\%20LA\%20EDUCACI\%D3N\%20SEXUAL\%20EN\%20ADOLESCENTE.\%20 INSTITUCI\%D3N\%20EDUCATIVA\%20SOLEDAD\%20ACOSTA\%20DE\%20SAMPER\%20DE\%20CARTAGENA.pdf;jsessionid=E95530FBEAEED3B88D491423398E E721? sequence $=1$

Bonilla Sanabria, P., Curvelo Jiménez, Y., Jiménez Sánchez, X., Torres Cariola, V., y Umba Puentes, F. (2005). El método de trabajo social en grupo en los proyectos de intervención de práctica de entrenamiento profesional. Revista Tendencias \& Retos, (10), 199-203.

Cartwright, D. (1983). Dinámica de grupos. Ed. Trillas.

Castellanos Martínez, S.E., y Tijaro Guio, D.M. (2011). Caracterización de los componentes de intervención profesional en los proyectos de práctica de entrenamiento profesional que incorporan el método de trabajo social de grupo. Programa de Trabajo Social, Universidad de la Salle, 2005-2010. [Tesis de grado, Universidad de La Salle, Bogotá, Colombia].

Cifuentes, R. M. (2011). Diseño de proyectos de investigación cualitativa. Noveduc.

Cifuentes, R. M. et al. (2010). Marco de fundamentación conceptual en trabajo social. Fundación Ciudad Don Bosco. 
Cifuentes, R.M., Pava, L.M., Rodríguez, C., Valenzuela, L.; Rodríguez, A.; Orjuela, C \& Vargas, R. (2001). Intervención de trabajo social. Avances y perspectivas. 1995-2000. Lectura crítica a Trabajos de Grado adelantados en Bogotá. Universidad de La Salle.

Coyle, G. (1935). What is social group work? Vcu libraries: Social Welfare - history project. https://socialwelfare.library.vcu.edu/social-work/social-group-work-and-change-1935/

Consejo General del Trabajo Social (2014). Definición internacional de trabajo social. https:// www.cgtrabajosocial.es/DefinicionTrabajoSocial

Consejo Nacional de Trabajo Social. (2015). Código de Ética de los Trabajadores Sociales en Colombia. Consejo Nacional de Trabajo Social.

Contreras de Wilhelm, Y. (2003). Trabajo social de grupos. Pax México.

Custo, E. y Tomasini, V. (2009). Teoría, espacio y estrategias de intervención grupal. Editorial Espartaco.

Custo, E. (2013). Asignatura: teoría, espacios y estrategias de intervención I (grupal), Programa teórico. Universidad Nacional de Córdoba.

Custo, E. (2017). Construcción de conocimientos en los espacios grupales en la contemporaneidad ¿Cuál es nuestro horizonte? Revista Margen, (86), 1-12.

Custo E., y Bilavcik, C. (2016). Reflexiones desde el trabajo social acerca del pensamiento crítico y autónomo en el campo profesional y grupal. Boletín Electrónico Surá, (236), 1-9.

Dell`Anno, A., y Teubal, R. (2006). Resignificando lo grupal en el trabajo social. Editorial Espacio.

Denzin, N.K. (1970). Sociological Methods. A Sourcebook. Aldine Publishing Company.

De Robertis, C. (1988). Metodología de la intervención en trabajo social. Librería El Ateneo.

De Robertis, C. (2003). Fundamentos del trabajo social: Ética y metodología. Nau Llibres.

De Robertis, C., y Pascal, H. (2007). La intervención colectiva en trabajo social. La acción con grupos y comunidades. Editorial Lumen Hvmanitas.

Eagleton, T. (2016). Esperanza sin optimismo. Editorial Taurus.

Fernández, A. M. (1985). El dispositivo grupal. Editorial Búsqueda.

Freire, P. (1976). Educación y cambio. Editorial Siglo XXI.

Galeano, M. E. (2004). Diseño de proyectos en la investigación cualitativa. Fondo Editorial Universidad EAFIT.

García, B., González, S., Quiroz, A. y Velázquez, Á. (2002). Técnicas interactivas para la investigación social cualitativa. Fundación Universitaria Luis Amigó. 
García Vergara, C.A., Jaimes Márquez, M.C., y Melo Barajas, S.L. (2017). Trabajo social y construcción de paz: un abordaje a las representaciones sociales del grupo de jóvenes escolares del Proyecto Rumbo de Paz. Documentos de Trabajo Social, (59), 140-169.

Gnecco de Ruíz, M.T (2005). Trabajo social con grupos. Fundamentos y tendencias. Editorial Kimpres Ltda.

Hernández Sampieri, R., Fernández Collado, C., y Baptista Lucio, M.P (2014). Metodología de la investigación. Interamericana Editores, S.A. de C.V.

Kisnerman, N. (1969). Servicio social de grupo. Una respuesta a nuestro tiempo. Hvmanitas.

Konopka, G. (1968). Trabajo social de grupo. Euramérica.

Lewin, Kurt. (1951). Teoría del campo en la ciencia social. Paidós editorial Ibérica.

Lockett, M. (2006). La experiencia de un grupo de mujeres en una casa de acogida: en busca de un punto de encuentro. En A. Dell'Anno, y R. Teubal (Comps.), Resignificando lo grupal en el trabajo social (pp.127-154). Editorial Espacio.

López Díaz, Y., Martínez Roa, A. y Peralta, L.J. (2009). Trabajo social de grupo: producción escrita, docencia y modelos de intervención. Universidad Nacional de Colombia.

López Peláez, A., y Fernández García, A. (2006). Trabajo social con grupos. Alianza Editorial S.A.

Maidana, G.I. (s.f.). La intervención profesional en trabajo social con Grupos. https:// es.scribd.com/document/462453685/La-Intervencion-Profesional-en-Trabajo-Socialcon-Grupos1

Martínez, A., y Peralta, L. (2006). Emergencia y desarrollo del trabajo social de grupo: una aproximación histórica. Revista del Departamento de Trabajo Social, (8), 63-71.

Marrugo Pomares, C.P. (2012). Educación ambiental basada en el uso eficiente y seguro de la energía en diez instituciones educativas de Cartagena de Indias 2012. Universidad de Cartagena, Facultad de Ciencias Sociales y Educación, Programa de Trabajo Social. Cartagena, Colombia.

Marx, C. y Engels, F. (2011). Manifiesto del partido comunista. Centro de estudios socialistas Carlos Marx.

Méndez Fernández, G. (septiembre, 2017). El conflicto en los grupos y la intervención desde el trabajo social. Aproximación a los discursos profesionales. Ponencia realizada en XVI Jornadas de Investigación de la Facultad de Ciencias Sociales, Universidad de la República, Montevideo.

Montoya, G. Zapata, C. y Cardona, N. (2002) Diccionario especializado de trabajo social. Universidad de Antioquia.

Murphy, M. (1959). The Social Group Work Method in Social Work Education. New York: Council on social work education. 
Oliva Carreras, M.A (2014). La práctica educativa del trabajo social en un contexto de encierro. Revista Cátedra Paralela, (11), 273-290.

Peralta, J.D. (2018). Educación popular y justicia comunitaria. Reflexiones desde el trabajo social. Revista Trabajo Social, 20(2), 119-138.

Pérez, J.F. (1998). Elementos para una teoría de la lectura. Revista Colombiana de Psicología, $7(1), 239-244$.

Pessacq, M.I., Castro, O., Contreras, M., y Triguero, M. (2018). La intervención grupal. Aportes de cátedra. Revista Margen, (91), 1-8.

Pichon-Rivière, E. (1988) El proceso grupal. Del psicoanálisis a la psicología social. Nueva Visión.

Ricoeur, P. (2006). Teoría de la interpretación. Discurso y excedente de sentido. Siglo XXI Editores.

Ruiz Huidobro, E.L., Zelarayán, M.E, y Jurado, J. (2017). Cátedra: práctica de trabajo social con grupos. Universidad Nacional de Tucumán, Facultad de Filosofía y Letras, Departamento de Trabajo Social.

Simon, C.I., Colque, R.C., Rada, L.S., Carrizo, E.A., Cruz, E.V., y López, E.A. (2018). La práctica de trabajo social con grupos en el proceso de implementación de la Licenciatura en Trabajo Social en la FHYCS de la UNJU: Una experiencia de intervención. Revista Difusiones, (14), 174-187.

Sepúlveda Cerna, M. C., y Vásquez Mendoza, V.A. (2015). Trabajo social con grupos: un análisis descriptivo del quehacer profesional en el área de salud mental. [Trabajo de pregrado, Universidad del Bío-Bío, Chillán, Chile].

Surianu Benítez, A.M. (2010). Análisis desde la ética en torno a los principios del trabajo social. Universidad Pontificia Bolivariana.

Teubal, R. (2006). Complejizando la mirada sobre lo grupal. Factores de cambio y aportes teórico-técnicos para la intervención. En A. Dell'Anno, y R. Teubal (Comps.), Resignificando lo grupal en el trabajo social (pp.51-74). Editorial Espacio.

Torcigliani, I., y Campana, M. (2009). Propuesta académica Teoría, espacios y estrategias de intervención I. Universidad Nacional de Córdoba, Facultad de Derecho y Ciencias Sociales, Escuela de Trabajo Social.

Torres Carrillo, Alfonso. 2007. Educación popular: Trayectoria y actualidad. Universidad Bolivariana de Venezuela.

Torres, J. (1988). Historia de trabajo social. Editores Colombia Ltda.

Torres Sánchez, C. (2002). Grupos, teorías y experiencias académicas. Universidad Industrial de Santander.

Valencia Arias, Y. (2015). Sistematización de experiencias de la práctica de trabajo social con grupo perteneciente a la Asociación Amigos con Calor Humano, Medellin 2015. (Trabajo 
de pregrado). Corporación Universitaria Minuto de Dios, Facultad de Ciencias Sociales y Humana, Programa Trabajo Social. Medellín, Colombia.

Varela Meneses, J. (2016). Informe final práctica académica de Trabajo Social III, Centro gerontológico "Dejando huellas", Santa Fe de Antioquia. Universidad de Antioquia.

Velásquez Morocho, N.C. (2017). El rol del trabajador social con grupos. [Trabajo de pregrado, Universidad de Cuenca, Ecuador].

Viscarret, J. (2007). Modelos de intervención en trabajo social. Alianza Editorial.

Vélez, O.L, y Galeano, M.E. (2002). Investigación cualitativa, Estado del Arte. Universidad de Antioquia.

Villa, O., Blanco, C.R., y Navarro, C. (2017). Trabajo social con grupos en las experiencias formativas. Períodos académicos 2015-2016. Interacción y perspectiva: Revista de Trabajo Social, 7(2), 233-252.

Vinter, R. (1969). Principios para la práctica del servicio social de grupo. Humanitas.

Zapata Ospina, S. (2016). Fortaleciendo la participación ciudadana, promoción de los derechos humanos. Informe final de la práctica profesional Corporación Conciudadanía. Universidad de Antioquia. 